\title{
Atitudes de risco do consumidor em restaurantes de auto-serviço
}

\section{Risk attitudes in self-service restaurants}

\section{R E S U M O}

\section{Objetivo}

O objetivo deste estudo foi avaliar as possibilidades de contaminação dos alimentos no balcão de distribuição, causada por usuários de Unidades Produtoras de Refeições.

\section{Métodos}

A coleta de informações foi realizada em 10 Unidades Produtoras de Refeições do Distrito Federal, via observação direta de 12 atitudes de risco cometidas pelos consumidores $(n=3.447)$, no período de outubro de 2003 a setembro de 2004. O horário selecionado para observação das atitudes foi o de maior movimento de cada unidade; a amostra foi sistematizada a cada 5 consumidores. 0 instrumento para coletar os dados relacionava as possíveis atitudes de risco de contaminação, no momento em que cada consumidor montava sua refeição.

\section{Resultados}

Os resultados obtidos demonstram que há probabilidade de contaminação alimentar causada por consumidores dos restaurantes de auto-serviço. Em $96 \%$ dos casos observados, os usuários não costumavam higienizar as mãos antes de se servirem. Observou-se também que não houve preocupação com o uso exclusivo de utensílios de servir por parte de $50 \%$ desses consumidores, enquanto $56 \%$ conversavam ou falavam sobre as preparações.

\section{Conclusão}

Conclui-se que é necessário conscientizar os consumidores, principalmente os usuários de auto-serviço, a fim de evitar a contaminação de alimentos e as possíveis ocorrências de toxinfecções alimentares.

Termos de indexação: contaminação de alimentos; higiene dos alimentos; restaurantes.

\footnotetext{
${ }^{1}$ Universidade de Brasília, Faculdade de Ciências da Saúde, Departamento de Nutrição. Campus Universitário Darcy Ribeiro Asa Norte, 70910-900, Brasília, DF, Brasil. Correspondência para/Correspondence to: R.P. ZANDONADI. E-mail: <renatapz@yahoo.com.br>.
} 


\section{A B S T R A C T}

\section{Objective}

The objective of this study is to evaluate the possible forms of food contamination by the costumer during the distribution period.

\section{Methods}

Data collection was performed in 10 food service units in Distrito Federal via direct observation of 12 risk attitudes $(n=3,447)$ between October 2003 and September 2004. The risk attitudes were observed during the peak hour of each restaurant; the sample was systematized for each 5 consumers. The data collection instrument related the possible risk attitudes of the consumers while serving themselves.

\section{Results}

The obtained results demonstrate that there is a probability of contamination of the food by the consumers in restaurants, especially because $96 \%$ of the observed individuals did not wash their hands before serving themselves. Furthermore, $50 \%$ of the consumers were not concerned with the exclusive use of utensils, while $56 \%$ talked about the foods.

\section{Conclusions}

The obtained data show that there is a need to improve the consumer's awareness, especially in self-service restaurants. Food contamination by consumers needs to be prevented in order to avoid food intoxication.

Indexing terms: food contamination; food hygiene; restaurants.

\section{N T R O D U Ç Ã O}

A alimentação é necessidade básica para qualquer sociedade. Influencia a qualidade de vida por ter relação com a manutenção, prevenção ou recuperação da saúde. Deve ser saudável, completa, variada, agradável ao paladar e segura para, assim, cumprir seu papel.

As transformações no mundo contemporâneo provocaram mudanças significativas na alimentação e nos hábitos alimentares dos seres humanos, que passaram a usufruir cada vez menos do universo doméstico. Essas mudanças foram ocasionadas por fatores que perpassam a urbanização, a industrialização, a profissionalização das mulheres, a elevação do nível de vida e de educação, 0 acesso mais amplo da população ao lazer, a redução do tempo para o preparo e/ou consumo do alimento, as viagens, entre outrosfatores ${ }^{1}$.

A preferência atual dos consumidores por refeições mais convenientes influenciou o mercado da alimentação coletiva. Ele cresce no mundo todo e, no Brasil, atende a mais de dois milhões de trabalhadores. Além da praticidade, 0 auto-serviço oferece refeições variadas e de baixo custo $^{2}$, permitindo ao consumidor compor o seu prato, de acordo com sua preferência.

Dados da Associação Brasileira da Indústria de Alimentos ${ }^{2}$ mostram que, do momento da implantação do Plano Real, em julho de 1994, até 2001 , houve um crescimento de $190,7 \%$ dos setores de serviços de alimentação e de 16,5\% dos de alimentação fora do lar. 0 número de restaurantes comerciais no Brasil duplicou na última década e movimentou $R \$ 5,2$ bilhões de reais, em 2001.

No entanto, o propósito das Unidades Produtoras de Refeições (UPR) não deve ser apenas alimentar o homem, mas "bem alimentá-lo". Isso significa não oferecer apenas produtos sensorialmente adequados, mas, sobretudo, produtos seguros em especial sob o aspecto higiênico-sanitário ${ }^{3}$. Nesse contexto, uma alimentação saudável preconiza a ingestão de alimentos com adequado controle higiênico-sanitário ${ }^{4,5}$ uma vez que a contaminação dos produtos pode provocar sérios danos à saúde, como as toxinfecções alimentares. 
A Organização Mundial de Saúde (OMS) define doença transmitida por alimento (DTA) como "uma doença de natureza infecciosa ou tóxica causada por, ou através do consumo de alimento ou água". Almeida Filho \& Rouquayrol ${ }^{7}$ definem surto como uma ocorrência epidêmica restrita a um espaço delimitado. Assim, surto de DTA é a ocorrência de dois ou mais casos que apresentem sintomas semelhantes após a ingestão de alimento ou água, de mesma origem, implicados como veículo da doença ${ }^{8}$, exceto em caso de botulismo, quando uma ocorrência única já é considerada um surto ${ }^{9}$.

A incidência de doenças relacionadas ao consumo de alimentos cresce anualmente; 0 número de refeições realizadas fora de casa potencializa o surgimento de doenças transmitidas por alimentos (DTA) e, conseqüentemente, os surtos de toxinfecções alimentares ${ }^{10}$. Para Smith \& Fratamico ${ }^{11}$, o consumo de refeições fora do domicílio é um dos fatores que mais contribuiu para o aumento da ocorrência de DTA uma vez que, nas Unidades Produtoras de Refeição (UPR), as refeições são produzidas em larga escala e torna-se mais difícil o controle efetivo de todas as preparações produzidas.

A contaminação dos alimentos se inicia na produção da matéria-prima e se estende às etapas de transporte, recepção, armazenamento. Durante a manipulação pode haver contaminação por condições precárias de higiene de manipuladores, equipamentos, utensílios, ambiente e condições inadequadas de armazenamento dos produtos prontos para consumo.

Vencida a etapa de preparação/industrialização, os alimentos continuam expostos à contaminação nos centros de distribuição, supermercados, restaurantes, nas mercearias e residências. De acordo com dados de Almeida ${ }^{12}$, mais de $70 \%$ dos casos de DTA têm origem na contaminação dos alimentos pelo seu consumidor final.

A higiene alimentar é fundamental para a garantia de qualidade dos produtos alimentícios e se insere em todas as operações relacionadas à manipulação de qualquer gênero alimentício; requer procedimentos apropriados no campo, na transformação, na distribuição e no consumo ${ }^{13}$.

No Brasil, a mão-de-obra recrutada para realização das atividades em UPR freqüentemente não é qualificada e, em muitos casos, sequer é treinada para assumir as atividades referentes à produção de refeições. De acordo com Arbache et al. ${ }^{14}, 22 \%$ da mão de obra é qualificada; $56 \%$ é não-qualificada e $22 \%$, semiqualificada. Ademais, observa-se também a falta de informação desses profissionais quanto às normas de segurança alimentar na produção de refeições.

Todavia, em um sistema de distribuição centralizado, como nos restaurantes de auto-serviço, há também a probabilidade de contaminação dos alimentos pelos consumidores, uma vez que estes mantêm contato direto com os alimentos expostos no balcão de distribuição.

Em UPR, os programas de capacitação de manipuladores enfatizam a importância da saúde individual e coletiva, incluem noções básicas de higiene pessoal e ambiental e destacam os danos que a ausência desses cuidados causam sobre a saúde do consumidor, conscientizando os manipuladores do seu papel na prevenção das DTA. Ressaltam, igualmente, a importância da conscientização dos consumidores sobre suas atitudes e, conseqüentemente, sobre os riscos de contaminação dos produtos em etapas posteriores às de produção e distribuição, para minimizar o aparecimento de DTA e prevenir o desperdício de produtos $^{15}$.

De acordo com Trigo ${ }^{16}$, verifica-se que a transgressão às regras fundamentais de lavagem das mãos - após usar sanitários, antes das refeições e em outras situações de risco - possibilita a contaminação de produtos. As mãos são importante veículo de contaminação, quando em contato com indivíduos, indivíduo e alimento, indivíduo e equipamento, utensílio, ambiente. 0 ato de espirrar sobre as mãos, ou sobre outra superfície qualquer, pode contaminar com uma quantidade importante de microorganismos.

A análise de perigos, a partir de instrumento que vise minimizar os riscos de contami- 
nação, contribuindo para a inocuidade do alimento, inclui, também, considerar os aspectos que fogem ao controle do processador, como por exemplo, 0 auto-serviço ${ }^{17}$.

Diante do exposto, e em virtude do impacto da alimentação fora do lar na sociedade moderna, foi desenvolvido um estudo em UPR para avaliar as atitudes de risco dos consumidores que podem favorecer a contaminação dos alimentos durante o auto-serviço.

\section{MÉTODOS}

Foi realizado um estudo exploratório com técnica de observação não participante, com amostragem de conveniência para a escolha das UPR e amostra sistematizada para a escolha dos consumidores observados. Foram selecionadas 10 UPR localizadas no Distrito Federal no ano de 2004, com cardápio médio e formal, participantes do estágio supervisionado em produção da Universidade de Brasília. O número de consumidores a serem observados em cada UPR foi determinado de modo a obter uma amostra representativa para uma população desconhecida ${ }^{18}$. Este número foi estimado, com um intervalo de confiança de 95\%, em 347 consumidores em cada UPR, tendo sido possível ampliar a amostra total para 5.348 consumidores, em virtude do retorno esperado do estudo para os responsáveis das UPR.

A pesquisa foi desenvolvida em três etapas: na primeira observou-se a lavagem das mãos pelos consumidores antes do auto-serviço, com amostra de 1.901 consumidores. Na segunda etapa, foi construído o instrumento a partir da observação e definição das atividades de risco e, na terceira etapa observaram-se as práticas das atitudes de risco por parte dos consumidores ( $n=3.447)$. Em cada UPR, a primeira etapa foi realizada em dois dias, baseando-se na observação do uso do lavatório localizado no refeitório pelos consumidores para lavagem das mãos, apesar de apenas cinco das UPR selecionadas disporem dessa estrutura.
Para elaboração do instrumento de observação das atitudes de risco, foram observadas as atitudes praticadas pelos consumidores, no momento do auto-serviço, em uma das UPR, por um período de uma semana. Treze atitudes de risco foram selecionadas e avaliadas pela técnica de juízes, cujas sugestões foram incorporadas ao instrumento definitivo ${ }^{19}$ a saber: a) não lavar as mãos imediatamente antes do auto-serviço; b) mexer no cabelo perto das preparações expostas no balcão; c) falar em cima das preparações no balcão de distribuição; d) deixar a gravata, a manga de camisas, bolsas, blusas, vestidos ou casacos tocarem nas preparações; e) deixar parte do corpo encostar nas preparações; f) tossir sobre as preparações; g) espirrar sobre preparações; h) utilizar o utensílio de uma preparação em outra já servida no prato do consumidor ; i) trocar os utensílios das preparações; j) deixar o utensílio cair dentro da preparação; I) retirar alimentos do seu prato e devolvê-los às cubas com a mão ou utensílio disponível; $\mathrm{m}$ ) consumir alimentos antes da pesagem; n) arrumar alimentos no prato com os utensílios das preparações.

A terceira etapa foi realizada durante três dias em cada UPR, e se ateve à observação e quantificação do número de consumidores que praticavam atitudes de risco no momento do auto-serviço. A observação foi efetuada a cada cinco indivíduos dentro do intervalo de uma hora, do período de maior movimentação do refeitório, indicado pelos nutricionistas dos estabelecimentos.

A análise dos dados foi realizada no programa Excel ${ }^{\circledR}$, que determinou o percentual de pessoas que praticavam as atitudes de risco em cada refeitório. 0 presente trabalho foi aprovado pelo Comitê de Ética em Pesquisa da Faculdade de Ciências da Saúde da Universidade de Brasília.

\section{RESULTADOSE DISCUSSÃ O}

A Tabela 1 apresenta o percentual de consumidores que cometeram atitudes de risco e o total de consumidores observados em todas as unidades investigadas. Com relação ao hábito de 
lavar as mãos, observou-se que $96 \%$ dos consumidores $(n=1.830)$ de 5 das 10 UPR analisadas, possuidoras de lavatórios e $100 \%$ dos consumidores $(n=253)$ da UPR 3 não higienizaram as mãos antes de iniciar o auto-serviço. As unidades 2, 4, 8, 9 e 10 não dispunham de lavatório para higienização das mãos no refeitório. Portanto, seus freqüentadores não foram considerados como consumidores que fazem a higienização das mãos antes do auto-serviço. Caso esses dados fossem considerados, o percentual de não conformidade seria de $98 \%$ ( $n=2.781$ ), em um universo de 2.852 indivíduos observados.

Vale ressaltar que aqueles que higienizavam as mãos nos lavatórios dos refeitórios das UPR, as enxugaram nas próprias roupas, atitude que possibilita uma recontaminação por meio do vestuário.

A transmissão de doenças infecciosas pelas mãos de manipuladores foi demonstrada há 120 anos. No entanto, somente em 1.938 as bactérias foram classificadas como residentes e transitórias ${ }^{20}$. Os microorganismos transitórios são princi- palmente bactérias gram-negativas, facilmente removidas pela adequada lavagem das mãos. Os residentes, em sua maioria gram-positivos, localizam-se em reentrâncias, nas quais os lipídios e o epitélio dificultam sua remoção pelos procedimentos de lavagem inadequada das mãos ${ }^{21}$.

Além das duas formas supramencionadas, a contaminação dos alimentos pode ocorrer ainda por meio de microrganismos patogênicos ou deteriorantes. 0 consumo de alimentos contaminados por microrganismos patogênicos pode levar o indivíduo a um quadro infeccioso, que pode variar de um desconforto leve a reações graves ou pode até mesmo levar à morte. Constituem também vias de eliminação de patógenos para os alimentos as infecções rinosinusiais por meio de gotículas de saliva emitidas ao falar, espirrar, tossir, e, sobretudo pelo contato oral, quando se prova o alimento $^{16}$. 0 couro cabeludo não coberto, as roupas e o próprio corpo podem também ser fontes de contaminação de patógenos, que, freqüentemente, possibilitam retrocontaminações dos alimentos ${ }^{16}$.

Tabela 1. Percentual de consumidores que praticaram atitudes de risco no momento da preparação de seus pratos em UPR* do Distrito Federal, 2004.

\begin{tabular}{|c|c|c|c|c|c|c|c|c|c|c|c|c|c|}
\hline \multirow{2}{*}{ Atitudes } & 1 & 2 & 3 & 4 & 5 & 6 & 7 & 8 & 9 & 10 & \multicolumn{3}{|c|}{ Total } \\
\hline & \multicolumn{10}{|c|}{$\%$} & $n^{a}$ & $\mathrm{n}^{\mathbf{b}}$ & $\%$ \\
\hline A & 8 & 6 & 0 & 23 & 4 & 10 & 0 & 2 & 0 & 3 & 235 & 3.447 & 7,0 \\
\hline B & 27 & 87 & 68 & 87 & 87 & 100 & 13 & 65 & 11 & 26 & 1.838 & 3.447 & 53,0 \\
\hline C & 17 & 12 & 0 & 14 & 0 & 0 & 7 & 1 & 0 & 3 & 336 & 2.412 & 14,0 \\
\hline$D$ & 11 & 10 & 2 & 2 & 2 & 0 & 19 & 1 & 0 & 3 & 214 & 3.447 & 6,0 \\
\hline$E$ & 0 & 1 & 0 & 0 & 0 & 0 & 6 & 1 & 0 & 0 & 14 & 3.447 & 0,4 \\
\hline $\mathrm{F}$ & 0 & 2 & 0 & 0 & 0 & 0 & 0 & 1 & 0 & 0 & 9 & 3.447 & 0,3 \\
\hline G & 55 & 74 & 13 & 81 & 54 & 55 & 59 & 43 & 0 & 14 & 1.730 & 3.447 & 50,0 \\
\hline $\mathrm{H}$ & 17 & 78 & 0 & 63 & 0 & 0 & 4 & 2 & 0 & 8 & 653 & 3.447 & 19,0 \\
\hline I & 18 & 3 & 1 & 1 & 0 & 0 & 6 & 1 & 6 & 9 & 304 & 3.447 & 9,0 \\
\hline J & 6 & 12 & 2 & 8 & 4 & 10 & 13 & 1 & 0 & 4 & 203 & 3.447 & 6,0 \\
\hline K & 4 & 3 & 4 & 3 & 0 & c & c & 2 & 0 & 3 & 99 & 3.177 & 3,0 \\
\hline $\mathrm{L}$ & 30 & 37 & 20 & 17 & 0 & 41 & 46 & 19 & 39 & 18 & 829 & 3.447 & 24,0 \\
\hline$M$ & 98 & d & 100 & d & 63 & 93 & 96 & d & d & d & 1.830 & 1.901 & 96,0 \\
\hline
\end{tabular}

* Unidades Produtoras de Refeições; aNúmero de pessoas que cometeu as atitudes; ${ }^{\text {b}}$ Total de pessoas observadas; 'Não havia pesagem das refeições; 'Não havia local para higienização das mãos no refeitório da UPR.

A: mexer no cabelo perto das preparações expostas no balcão; B: falar em cima das preparações no balcão de distribuição; C: deixar a gravata, a manga de camisas, bolsas, blusas, vestidos ou casacos tocarem nas preparações; D: deixar parte do corpo encostar nas preparações; E: tossir sobre as preparações; F: espirrar sobre preparações; G: utilizar o utensílio de uma preparação em outra já servida no prato do consumidor; H: trocar os utensílios das preparações; I: deixar o utensílio cair dentro da preparação; J: retirar alimentos do seu prato e devolver às cubas com a mão ou utensílio disponível; K: consumir alimentos antes da pesagem; L: arrumar alimentos no prato com os utensílios das preparações; M: não lavar as mãos imediatamente antes do auto-serviço. 
Tal ciclo de contaminação possibilita a ocorrência de eventos que desencadearão situações desagradáveis, tais como a decomposição de alimentos e o aparecimento de DTA. Para controlar esses episódios, recomenda-se que sejam adotadas medidas que objetivem garantir a inocuidade dos alimentos, fundamentadas sempre no controle de riscos potenciais de contaminação.

Por essas razões, na produção de alimentos é fundamental que o manipulador, ao ser capacitado, seja alertado sobre a importância da higiene pessoal e da higiene durante a manipulação dos alimentos, e sobre a necessidade de sempre lavar as mãos antes de iniciar uma atividade ou trocar de atividade após usar o banheiro, tossir, espirrar, assoar o nariz, ou tocar ferimentos e curativos. Para tornar viável e facilitar a higiene pessoal ${ }^{21}$, 0 estabelecimento deve disponibilizar pias, sabonetes líquidos, papel-toalha, tanto na área de manipulação de produtos como na área de consumo. Assim, a falta de lavatórios para higienização das mãos dos consumidores é falha estrutural grave nas UPR. Para solucionar 0 problema, cabe ao nutricionista buscar alternativas, como a adoção do uso de géis bactericidas ${ }^{22}$ na entrada das unidades.

De acordo com a Organização M undial de Saúde ${ }^{23}$, nos países industrializados, anualmente, uma em cada três pessoas é afetada por doenças veiculadas por alimentos, resultando em sofrimento humano e em perdas econômicas que giram em torno de alguns bilhões de dólares. 0 consumo de alimentos seguros leva à redução do número de casos de doenças alimentares, de custos na saúde pública, de barreiras ao comércio internacional, de perdas, e à melhor produtividade ${ }^{24}$.

Grande parte dos casos de infecções alimentares resulta da associação entre o consumo de alimentos que sofrem manipulação inadequada e as más condições de armazenamento, acondicionamento e distribuição, que permitem a exposição direta ao ambiente, propiciando a contaminação e posterior veiculação de agentes de natureza infecciosa aos consumidores ${ }^{25}$. De acordo com dados do M inistério da Saúde ${ }^{8}$, restaurantes e refeitórios foram responsabilizados por $49 \%$ dos surtos de DTA no Distrito Federal em 2003, vindo a seguir refeições realizadas em domicílios, equivalente a $27 \%$, no mesmo período. As escolas correspondem a $6 \%$ e as festas, a $12 \%$.

A análise dos dados da Tabela 1 permite inferir que os consumidores dessas unidades constituem importante fonte de contaminação de alimentos, tendo em vista que é possível veicular microorganismos com a simples atitude de mexer nos cabelo perto das preparações $(7 \%$ dos consumidores), seja pelo contato direto do cabelo que cai sobre a preparação, seja por sua transmissão ao ambiente. Assim também, como na boca há diversos tipos de microorganismos, a atitude de tossir, cantar ou falar sobre os alimentos é tão contaminante quanto espirrar. Os microorganismos provenientes das gotículas de saliva expelidas quando alguma dessas atitudes ocorre, podem depositar-se sobre os alimentos contaminando-os. A roupa, as partes do corpo e os demais objetos são igualmente veiculadores de microorganismos aos alimentos. Verificou-se que muitos consumidores não se preocupam com tais detaIhes, tornando possível a contaminação por essas vias.

Encostar utensílios de uma preparação em outras que já se encontram dentro do prato, trocar utensílios das preparações, devolver parte das preparações que estavam dentro do prato em contato com outras às cubas, foram atitudes observadas nas diferentes UPR, e que comprometem a segurança do alimento. 0 risco de contaminação torna-se potencializado quando 0 utensílio é deixado dentro da preparação, pois a parte usada para segurá-lo entra em contato com as mãos não higienizadas do usuário. $\mathrm{A}$ isso alia-se, ainda, o fato de o funcionário efetuar a reposição da preparação sem trocar a cuba, principalmente se não houver um controle adequado da temperatura de exposição do alimento e se sua reposição não acontecer com a devida freqüência. Cardoso et al. ${ }^{26}$ verificaram que 9 das 18 unidades avaliadas na Bahia mantinham a temperatura de conservação dos balcões térmicos inferior a $60^{\circ} \mathrm{C}$, com tempo de exposição médio de 3 horas. Dessa forma, há um risco quando não 
se trocam as cubas na reposição, ou quando os utensílios contaminados atingem as preparações.

0 consumo de alimentos antes da pesagem do prato também é outra fonte importante de contaminação, pois as preparações são levadas à boca com as mãos. Logo após essa operação, 0 mesmo consumidor manuseia os utensílios disponíveis no balcão.

Essas atitudes levam a crer que o risco de contaminação de preparações não é monitorado nas UPR analisadas. Além disso, quando o fluxo de consumidores diminui, as preparações que podem estar contaminadas ficam expostas por um tempo maior, possivelmente em temperatura favorável ao desenvolvimento microbiano.

Há alguns anos, no Brasil, verifica-se a incidência de surtos provocados por alimentos contaminados por Staphylococcus, que estão sendo reconhecidos e estudados devido à sua grande incidência ${ }^{27}$. A intoxicação causada por alimentos contendo enterotoxinas de Staphylococcus aureus é um dos tipos mais comuns de doenças de origem alimentar em todo o mundo. Como se trata de uma doença de curso rápido e não muito grave, os indivíduos afetados, geralmente, não necessitam de atendimento médico e a maioria dos casos não é notificada, não obstante o fato de ocasionar absenteísmo no trabalho ${ }^{28}$.

Os estafilococos destacam-se como importante grupo entre os microrganismos Gram positivos. A presença deles é observada sobretudo na pele e nas mucosas dos seres humanos. Estudo realizado por Pereira et al. ${ }^{29}$, com 55 indivíduos, mostrou que 58,2\% deles apresentavam Staphylococcus aureus e 30,9\% apresentavam material enterotoxigênico no nariz, em torno e embaixo das unhas.

Nesta pesquisa, o perfil de risco para contaminação não foi homogêneo em todas as UPR. Na UPR 8, por exemplo, verificou-se que, de maneira geral, não havia muitos problemas com relação à higiene no momento da distribuição, em virtude da presença de vidro de proteção no balcão de distribuição e de uma distância relati- vamente maior entre o consumidor e a preparação, dificultando um contato muito próximo com 0 alimento. Esse fato permite deduzir, portanto, que o hábito de conversar enquanto estão servindo seus pratos - observado em $65 \%$ dos consumidores - pode não ser uma atitude de risco. Nessa unidade, os pontos mais críticos foram a troca de utensílios das preparações, ocorrida em $43 \%$ dos casos avaliados, e o uso inadequado dos utensílios de servir por parte de $19 \%$ dos indivíduos observados.

Identificou-se, também, que debruçar-se sobre os pratos é um hábito comum dos consumidores, especialmente quando as cubas oferecem preparações diferentes em cada um dos lados do balcão de serviço.

\section{O N C LU SÃ O}

A prevenção da contaminação dos alimentos não é tarefa exclusiva dos manipuladores de alimentos, pois os consumidores também desempenham papel importante na cadeia analisada.

A partir dos resultados obtidos, identificou-se a necessidade de os consumidores serem conscientizados sobre as atitudes apropriadas durante a montagem de seus pratos, a fim de serem evitadas não só possíveis contaminações como também as doenças transmitidas por alimentos contaminados.

Assim, conclui-se que a higiene pessoal do consumidor é o principal fator a ser monitorado e a instalação de lavatórios, com instrução para uso apropriado, a principal solução a ser adotada. A adoção de balcões térmicos com barreiras de vidro apresenta-se como uma solução para evitar que os usuários dos auto-serviços contaminem as preparações.

\section{REFERÊ N CIAS}

1. Akutsu RC, Botelho RA, Camargo EB, Sávio KEO, A raújo WC. Adequação das boas práticas de fabricação em serviços de alimentação. Rev Nutr. 2005; 18(5):669-80. 
2. Associação Brasileira das Indústrias da Alimentação. Mercado de Food Service no Brasil. 2002 [acesso em 20 fev 2002]. Disponível em: http://w ww.abia.org.br

3. Proença RPC. Novas tecnologias para a produção de refeições coletivas: recomendações de introdução para a realidade brasileira. Rev Nutr. 1999; 12(1):43-53.

4. Silva Júnior EA. Manual de controle higiênico sanitário em alimentos. São Paulo: Livraria Varela; 2002.

5. Akutsu RC, Botelho RA, Camargo EB, Sávio KE, Araújo WC. A ficha técnica de preparação como instrumento de qualidade na produção de refeições. Rev Nutr. 2005; 18(2):277-9.

6. Organização Mundial de Saúde. Foodborne disease. 2001. [cited $2005 \mathrm{M}$ ar 5]. Available from: http://www.who.int

7. Almeida Filho N, Rouquayrol MZ. Introdução à epidemiologia moderna. Belo Horizonte: COOPMED; 1992.

8. Brasil. M inistério da Saúde. Doenças transmitidas por alimentos. 2004 [acesso em 28 nov 2005]. Disponível em: http://www.saude.df,.gov.br

9. Bryan FL. Risks associated with vehicles of foodborne pathogens and toxins. J Food Protect. 1988; 51(6):498-508.

10. Lynch RA, Elledge BL, Griffith CC, Boatright DT. A comparison of food safety knowledge among restaurant managers, by source of training and experience, in Oklahoma County. J Environ Health. 2003; 66(2):9-14.

11. Smith DL, Fratamico PM. Factors involved in the emergence and persistence of food diseases. J Food Protect. 1997; 40(6):415-22.

12. Almeida CR. O sistema HACCP como instrumento para garantir a inocuidade dos alimentos. Higiene Alimentar. 1998; 12(53):12-20.

13. Hobbs BC, Roberts D. Toxinfecções e controle higiênico sanitário de alimentos. São Paulo: Livraria Varela; 1999.

14. Arbache J, Telles V, Silva N. Economia brasileira e gastronomia. In: Araújo W, Tenser C. Gastronomia: cortes e recortes. Brasília: Senac; 2006.

15. Proença RPC, Veiros MB, Smith LK . Legislação portuguesa e brasileira de segurança e higiene dos alimentos: panorama atual. Higiene Alimentar. 2006; 20(145):112-22.

16. Trigo, VC. Manual prático de higiene e sanidade das unidades de alimentação e nutrição. São Paulo: Livraria Varela; 1999.

17. Queiroz ATA, Rodrigues CR, Alvarez GG, Kakisaka LT. Boas práticas de fabricação em restaurantes "self-service" a quilo. Higiene Alimentar. 2000; 14(78):48-9.

18. Costa Neto, PLO. Estatística. São Paulo: Edgard Blücher; 2002.

19. Erthal TC. Manual de psicometria. Rio de Janeiro: Jorge Zahar; 1987.

20. Almeida RCC, Kuaye AY, Serrano AM, Almeida PF. Avaliação e controle da qualidade microbiológica de mãos de manipuladores de alimentos. Rev Saúde Pública. 1995; 29(4):290-4.

21. Tauxe RV. Suveillance and investigation of foodborne diseases: roles for public health in meeting objectives for food safety. Food Control. 2002; 13(6-7):363-9.

22. Hernandes SED, M ello AC, Sant'Ana JJ, Soares VS, Cassiolato V, Garcia LB, et al. Eficácia do álcool gel e outros agentes degermantes na remoção de importantes patógenos hospitalares aplicados artificialmente nas mãos. Braz J Microbiol. 2004; 35(1-2): 33-9.

23. Organização Mundial de Saúde. Nutrition, food security and safety. 1999 [cited 2005 Feb 20]. Available from: http://www.wpro.who.int/NR/ rdonlyres/5E6C8976-6030-47AA-A 37 B4E0BBB46324C/0/chapter4_43.pdf

24. Mosupye FM, Von Holy A. M icrobiological quality and safety of street-vended foods in Johannesburg city, South Africa. J Food Protect. 1999; 62:1278-84.

25. Rodrigues MM, Bertin BMA, Assis L, Duarte EB, Avelar AM O, Paixão JTS, et al. Indícios de Rotavirus na etiologia de um surto de infecção de origem alimentar. Ciência Tecnol Alim. 2004; 24(1):88-93.

26. Cardoso RCV, Souza EVA, Santos PQ. Unidades de alimentação e nutrição nos campi da Universidade Federal da Bahia: um estudo sob a perspectiva do alimento seguro. Rev Nutr. 2005; 18(5):669-80.

27. Carmo LS, Dias RS, Linardi VR, Sena MJ, Santos DA. An Outbreak of staphylococcal food poisoning in the municipality of Passos, M G, Brazil. Braz Arch Biol Tecnol. 2003; 46(4):581-6.

28. Rodrigues $\mathrm{KL}$, Moreira $\mathrm{AN}$, Almeida ATS, Chiochetta D, Rodrigues MJ, Brod CS, et al. Intoxicação estafilocócica em restaurante institucional. Ciência Rural. 2004; 34(1):297-9.

29. Pereira ML, Carmo LS, Lara MA, Silva SO, Dias RS, Bergdoll MS. Enterotoxigenic Staphylococci from food handlers working in an industrial kitchen in Belo Horizonte-M G (Brasil). Rev Microbiol. 1994; 25:161-5.

Recebido em: 29/7/2005

Versão final reapresentada em: 30/10/2006 Aprovado em: 21/11/2006 